\title{
The Protective Effect of Fluorofenidone against Cyclosporine A-Induced Nephrotoxicity
}

\author{
Yang Chen $^{a}$ Nasui Wang ${ }^{b}$ Qiongjing Yuan ${ }^{a}$ Jiao Qin ${ }^{c}$ Gaoyun Hu${ }^{d}$ \\ Qianbin Li ${ }^{d}$ Lijian Tao ${ }^{a}$ Yanyun Xie ${ }^{a}$ Zhangzhe Peng ${ }^{a}$ \\ a Department of Nephrology, Xiangya Hospital, Central South University, Changsha, China; \\ ${ }^{b}$ Division of Endocrinology and Metabolism, Department of Medicine, The First Affiliated \\ Hospital of Shantou University Medical College, Shantou, China; ' $D$ epartment of \\ Nephrology, Changsha Central Hospital, Changsha, China; dDepartment of Medicinal \\ Chemistry, Xiangya School of Pharmacy, Central South University, Changsha, China
}

\section{Keywords}

Renal tubulointerstitial fibrosis · Apoptosis · Fluorofenidone · Cyclosporine A

\begin{abstract}
Background/Aims: Cyclosporine A (CsA) is an immunosuppressant drug that is used during organ transplants. However, its utility is limited by its nephrotoxic potential. This study aimed to investigate whether fluorofenidone (AKF-PD) could provide protection against CsAinduced nephrotoxicity. Methods: Eighty-five male Sprague-Dawley rats were divided into 5 groups: drug solvent, CsA, CsA with AKF-PD (250, $500 \mathrm{mg} / \mathrm{kg} /$ day), and CsA with pirfenidone (PFD, $250 \mathrm{mg} / \mathrm{kg} /$ day). Tubulointerstitial injury index, extracellular matrix (ECM) deposition, expression of type I and IV collagen, transforming growth factor (TGF)- $\beta 1$, platelet-derived growth factor (PDGF), Fas ligand (FASL), cleaved-caspase-3, cleaved-poly(ADP-ribose) polymerase (PARP)-1, and the number of transferase-mediated nick end-labeling (TUNEL)-positive renal tubule cells were determined. In addition, levels of TGF- $\beta 1, F A S L$, cleaved-caspase-3, cleaved-PARP-1, and number of annexin V-positive cells were determined in rat proximal tubular epithelial cells (NRK-52E) treated with CsA $(20 \mu \mathrm{mol} / \mathrm{L})$, AKF-PD $(400 \mu \mathrm{g} / \mathrm{mL})$, PFD $(400$ $\mu \mathrm{g} / \mathrm{mL}$ ), and GW788388 (5 $\mu \mathrm{mol} / \mathrm{L})$. Results: AKF-PD (250, $500 \mathrm{mg} / \mathrm{kg} /$ day) significantly reduced tubulointerstitial injury, ECM deposition, expression of type I and IV collagen, TGF- $\beta 1$, PDGF, FASL, cleaved-caspase-3, cleaved-PARP-1, and number of TUNEL-positive renal tubule cells in the CsA-treated kidneys. In addition, AKF-PD $(400 \mu \mathrm{g} / \mathrm{mL})$ significantly decreased TGF- $\beta 1$, FASL, cleaved-caspase-3, and PARP-1 expression in NRK-52E cells and further reduced the number of annexin V-positive cells. Conclusion: AKF-PD protect kidney from fibrosis and apoptosis in CsA-induced kidney injury.




\section{Kidney \\ Blood Pressure \\ Research}

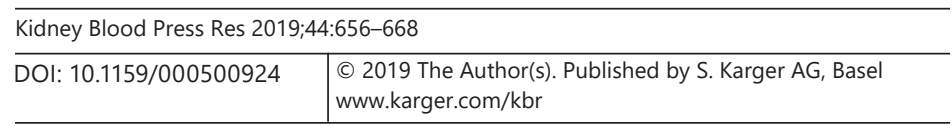

Chen et al.: The Protective Effect of AKF-PD against CsA-Induced Nephrotoxicity

\section{Introduction}

Cyclosporine A ( $\mathrm{Cs} \mathrm{A})$ is an immunosuppressive drug commonly employed during organ transplant procedures, in part owing to its unique ability to suppress $\mathrm{T}$ cell responses without impairing myeloid cell activity [1]. Nevertheless, its administration is limited by its nephrotoxic potential [2]. Prolonged use of CsA can result in nephrotoxicity that is progressive, with permanent lesions forming that are associated with striped interstitial fibrosis and tubular atrophy [3].

Recent studies showed that apoptosis plays an important role in the pathogenesis of the chronic CsA lesion [4]. Proapoptotic signaling induced by CsA can be triggered through the extrinsic pathway, in which Fas ligand (FasL, CD95L) binds to and crosslinks the Fas receptor on the surface of target cells, activating an intracellular caspase cascades that can lead to tubular cell apoptosis [5-8].

Additionally, CsA directly upregulates transforming growth factor (TGF)- $\beta 1$ expression in tubular epithelial cells $[9,10]$. TGF- $\beta 1$ is central to the fibrotic process. TGF- $\beta 1$ signaling promotes the synthesis of extracellular matrix (ECM) proteins, including fibronectin and collagens [11]. This ECM proteins production along with localized apoptosis is a major driver of renal tubular atrophy and tubulointerstitial fibrosis owing to the death of resident renal cells [12-14]. Previous studies have shown that TGF- $\beta 1$-induced apoptosis is driven by the upregulation of FasL in NRK-52E cells [15].

Fluorofenidone (AKF-PD; 1-[3-fluorophenyl]-5-methyl-2-[1H]-pyridone), a drug that has been demonstrated to possess multiorgan antifibrotic activity in the kidney [16-20], lung $[21,22]$, and liver [23, 24], offering the potential for renal protection. Moreover, previous study from our laboratory indicated that AKF-PD can inhibit Ang II-induced apoptosis of renal tubular cells through blockage of the Fas/FasL pathway [25]. Pirfenidone (PFD) has also been reported to attenuate renal fibrosis, preventing tubular cell apoptosis in a rat model CsAinduced chronic nephrotoxicity [26]. AKF-PD is structurally similar to PFD [27], and these 2 drugs further have similar antifibrotic activity [20].

In this article, we studied the effect of AKF-PD on renal structural and functional alterations induced by CsA and assessed whether the protective effect was associated with antifibrotic and antiapoptotic effects.

\section{Materials and Methods}

\section{Antibodies and Reagents}

Invitrogen (Carlsbad, CA, USA) was the source of all high glucose DMEM, fetal bovine serum (FBS), and penicillin/streptomycin. Antibodies against FasL were from Santa Cruz (Cambridge, MA, USA), while those against cleaved caspase-3 and PARP were from Cell Signaling Technology (Danvers, MA, USA). Collagen I and IV were purchased from Abcam (UK). Anti-glyceraldehyde-3-phosphate dehydrogenase (GAPDH) and CsA came from Sigma-Aldrich (St. Louis, MO, USA). TGF- $\beta$ type I receptor inhibitor GW788388 was from Selleck (Shanghai, China). The Jackson Laboratory (Bar Harbor, ME, USA) was the source of horseradish peroxideconjugated secondary antibodies. Life Technologies (Carlsbad, CA, USA) was the source of Trizol, RevertAid First Strand cDNA Synthesis Kit, and Lipofectamine 2000. The SYBR green real-time polymerase chain reaction (PCR) kit came from Takara (Dalian, Liaoning, China). Roche (Mannhein, Germany) was the source of the transferase-mediated nick end-labeling (TUNEL) in Situ Cell Death Detection Kit, and the FITC Annexin V Apoptosis Detection Kit I was from BD Pharmingen (UK).

Animals

A total of 85 male Sprague-Dawley rats (215-500 g) from the Silaike Laboratory Animal (Shanghai, China) were housed under standard conditions, receiving a low-salt diet ( $0.05 \%$ sodium). CsA was dissolved in olive oil (Sinopharm chemical reagent, Shanghai, China) at $15 \mathrm{mg} / \mathrm{mL}$. Randomization was used to divide 


\section{Kidney \\ Blood Pressure Research}

\begin{tabular}{l|l}
\hline Kidney Blood Press Res 2019;44:656-668 \\
\hline DOI: 10.1159/000500924 & $\begin{array}{l}\text { @ 2019 The Author(s). Published by S. Karger AG, Basel } \\
\text { www.karger.com/kbr }\end{array}$ \\
\hline
\end{tabular}

Table 1. The primers used for real-time PCR

\begin{tabular}{lll}
\hline Genes & Forward primer $\left(5^{\prime}-3^{\prime}\right)$ & Reverse primer $\left(5^{\prime}-3^{\prime}\right)$ \\
\hline Collagen I & TTGGGATGGAGGGAGTTTACACGA & TCAGGGGCGAAGGCAACAGT \\
Collagen IV & ATTCCTTTGTGATGCACACCAG & AAGCTGTAAGCATTCGCGTAGTA \\
TGF- $\beta 1$ & CAACAATTCCTGGCG TTACCTT & AAGCCCTGTATTCCGTCTCCTT \\
PDGF & CTGAGCTGGACTTGAACATG & GCACTCGGCGATTACGG \\
$\beta$-Actin & GGAGATTACTGCCCTGGCTCCTA & GACTCATCGTACTCCTGCTTGCTG \\
\hline
\end{tabular}

PCR, polymerase chain reaction; TGF, transforming growth factor.

rats into 5 groups: drug solvent-treated males ( $n=17)$; CsA-treated males ( $15 \mathrm{mg} / \mathrm{kg} / \mathrm{day}, n=17)$; CsA with AKF-PD treated males $(250,500 \mathrm{mg} / \mathrm{kg} /$ day, $n=17)$; and CsA with PFD treated males $(250 \mathrm{mg} / \mathrm{kg} / \mathrm{day}, n=$ 17). Synthesis of both AKF-PD and PFD was completed by the School of Pharmaceutical Sciences, Central South University. AKF-PD and PFD were both dissolved and diluted using $0.5 \%$ carboxymethyl cellulose sodium. Drug- and vehicle-treated groups received an oral gavage once daily beginning 18 days after injection. All rats were ultimately euthanized 36 days after the injection $(n=85)$. The left kidney of each rat was collected, and half was fixed using $4 \%$ paraformaldehyde prior to paraffin embedding. Sections ( $4 \mu \mathrm{m}$ thick) were cut for use in immunohistochemistry (IHC) and TUNEL staining procedures. The remaining kidney was snap frozen and was used for all quantitative PCR and Western blotting.

All animal protocols were compliant with NIH guidelines and met with the approval of the Institutional Animal Care and Use Committee of Xiangya School of Medicine, Central South University.

Renal Pathology and IHC

Paraffin sections were hematoxylin and eosin stained or were instead stained using Masson's trichrome, with hematoxylin and eosin sections being used to investigate renal tubulointerstitial injury in a semiquantitative manner [28]. Masson's stained sections were graded as previously described to assess collagen deposition [29]. The DAKO EnVision System (Dako Diagnostics, Zug, Switzerland) was used to complete all IHC studies. Initially, sections were stained with anticollagen I (1:500), or anticollagen IV (1:800). A blinded observer then assessed the degree of collagen staining via computerized morphometry with the Image Pro-Plus 6.0 software package (Media Cybernetics, Bethesda, MD, USA).

TUNEL Assay

Tubular epithelial cell apoptosis was assessed via terminal deoxynucleotidyl TUNEL staining. Tissue sections were processed according to the provided protocol, and TUNEL + cells in 10 fields $(\times 100)$ were independently counted by 2 blinded researchers.

\section{Real-Time PCR}

Trizol was employed to isolate total kidney RNA based on provided protocols, and $1 \mu \mathrm{g}$ of this RNA served as a template to synthesize cDNA with the ReverseAid first-strand cDNA synthesis kit. The SYBR Green PCR reagent kit was then used with an ABI Model 7900 Sequence Detector (Applied Biosystems, Foster City, CA, USA) to assess mRNA expression following normalization to $\beta$-actin, further calculation and statistical analysis were based on the comparative $2^{-\Delta \Delta C T}$ method. Primer sequences were shown in Table 1.

\section{Cell Culture}

NRK-52E cells from the American Type Culture Collection (Rockville, MD, USA) were grown under standard incubator conditions in DMEM containing 10\% FBS, $100 \mathrm{U} / \mathrm{mL}$ penicillin, and $100 \mu \mathrm{g} / \mathrm{mL}$ streptomycin. Cells were seeded in 12-well plates in complete medium for $24 \mathrm{~h}$ and were then switched to DMEM containing 2\% FBS for $16 \mathrm{~h}$. These synchronized NRK-52E cells were then separated into the following 5 groups: (1) control group: DMEM without CsA, AKF-PD, PFD or GW788388; (2) CsA (20 $\mu \mathrm{mol} / \mathrm{L})$ group: CsA $(20 \mu \mathrm{mol} / \mathrm{L})$-treated group without AKF-PD, PFD or GW788388; (3) AKF-PD (400 $\mu \mathrm{g} / \mathrm{mL})$ group: DMEM containing CsA $(20 \mu \mathrm{mol} / \mathrm{L})$ and AKF-PD $(400 \mu \mathrm{g} / \mathrm{mL})$; (4) PFD $(400 \mu \mathrm{g} / \mathrm{mL})$ group: DMEM containing CsA $(20 \mu \mathrm{mol} / \mathrm{L})$ and PFD ( $400 \mu \mathrm{g} / \mathrm{mL})$; (5) GW788388 (5 $\mu \mathrm{mol} / \mathrm{L})$ group: DMEM containing CsA $(20 \mu \mathrm{mol} / \mathrm{L})$ and GW788388 (5 $\mu \mathrm{mol} / \mathrm{L})$. After $24 \mathrm{~h}$, cells were harvested for further analysis. 
Table 2. Changes in renal functional parameters

\begin{tabular}{llll}
\hline Group & $n$ & BUN, mmol/L & PCr, $\mu \mathrm{mol} / \mathrm{L}$ \\
\hline Control & 16 & $6.73 \pm 0.98$ & $49.50 \pm 6.83$ \\
CsA & 15 & $15.06 \pm 3.21^{*}$ & $63.04 \pm 9.10^{*}$ \\
CsA+AKF-PD 250 $\mathrm{mg} \times \mathrm{kg}^{-1} \times \mathrm{d}^{-1}$ & 13 & $17.16 \pm 5.16^{*}$ & $62.24 \pm 11.96^{*}$ \\
CsA+AKF-PD 500 ${\mathrm{mg} \times \mathrm{kg}^{-1} \times \mathrm{d}^{-1}}_{\text {CsA+PFD 250 mg } \times \mathrm{kg}^{-1} \times \mathrm{d}^{-1}}^{16}$ & $18.09 \pm 11.33^{*}$ & $61.18 \pm 6.65^{*}$ \\
\hline
\end{tabular}

All data are presented as means \pm SD. ${ }^{*} p<0.05$ versus control. BUN, blood urea nitrogen; CsA, cyclosporine A; PCr, plasma creatinine; AKF-PD, fluorofenidone; PFD, pirfenidone.

Assessment of Apoptosis

Annexin V-FITC/propidium iodide (PI) was employed to stain NRK-52E cells for apoptosis. Briefly, harvested cells were washed 2 times using cold PBS and incubated for 15 min in a binding buffer while protected from light with annexin V-FITC and PI. Staining was then assessed via flow cytometry (BD FACSCanto II UK).

Western Blot

Western blotting to assess levels of various proteins in renal or cell line samples were performed as previously described [16, 30]. Protein concentration was determined according to the manufacturer's protocol using the BCA Protein Assay Kit. Proteins were analyzed by 10 or $12 \%$ sodium dodecyl sulfate-polyacrylamide gel electrophoresis and transferred to polyvinylidene fluoride membranes (Millipore, USA). The membranes were incubated in a solution of Tris-buffered-saline (TBS) containing $5 \%(\mathrm{w} / \mathrm{v})$ bovine serum albumin and $0.1 \%$ Tween-20 (TBST) for $1 \mathrm{~h}$ at room temperature before incubation overnight at $4{ }^{\circ} \mathrm{C}$ with primary antibodies against FasL (1:1,000), cleaved caspase-3 (1:1,000), cleaved PARP $(1: 1,000)$, or GAPDH $(1: 5,000)$. Membranes were washed 3 times with TBST. After washing, they were incubated with horseradish peroxide-conjugated secondary antibodies for $1 \mathrm{~h}$ at room temperature. After washing 3 times with TBST, the membrane was then visualized using an enhanced chemiluminescent technique according to the manufacturer's instructions.

\section{Statistical Analyses}

All data are means \pm SD, with SPSS version 18.0 (SPSS Inc., IL, USA) being used for all statistical testing. Between-group comparisons were via one-way ANOVA, with $p<0.05$ being the statistical significance threshold.

\section{Results}

\section{Functional Parameters}

Changes in functional parameters after CsA treatment are shown in Table 2. In rats, CsA increased levels of both plasma creatinine and blood urea nitrogen relative to control group. AKF-PD (250, $500 \mathrm{mg} / \mathrm{kg} /$ day) or PFD (250 mg/kg/day) treatment had no effects on these parameters.

\section{AKF-PD Attenuated Tubulointerstitial Injury and Fibrosis in CsA-Induced Nephropathy}

Although vehicle-treated rats demonstrated normal kidney histology, CsA led to tubulointerstitial injury, as characterized by tubular dilatation and atrophy, infiltration by inflammatory cells into the interstitium, and localized fibrosis. AKF-PD treatment at either dose significantly decreased injury to tubulointerstitial structures as compared to CsA-treated rats. PFD $(250 \mathrm{mg} / \mathrm{kg} /$ day) similarly reduced injury scores relative to rats treated with CsA alone (Fig. 1A). Kidney ECM deposition was assessed via Masson's trichrome staining, 
Kidney

Blood Pressure Research

\begin{tabular}{l|l}
\hline Kidney Blood Press Res 2019;44:656-668 \\
\hline DOI: 10.1159/000500924 & $\begin{array}{l}\text { @ 2019 The Author(s). Published by S. Karger AG, Basel } \\
\text { www.karger.com/kbr }\end{array}$ \\
\hline
\end{tabular}

Chen et al.: The Protective Effect of AKF-PD against CsA-Induced Nephrotoxicity

A

control

CsA

CsA+AKF-PD 250/mg/kg/d

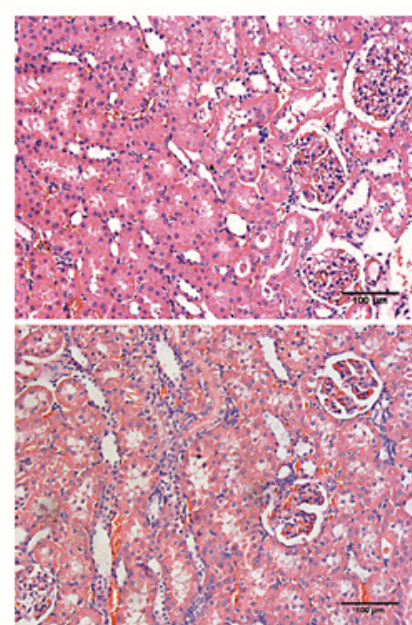

CsA+AKF-PD 500mg/kg/d

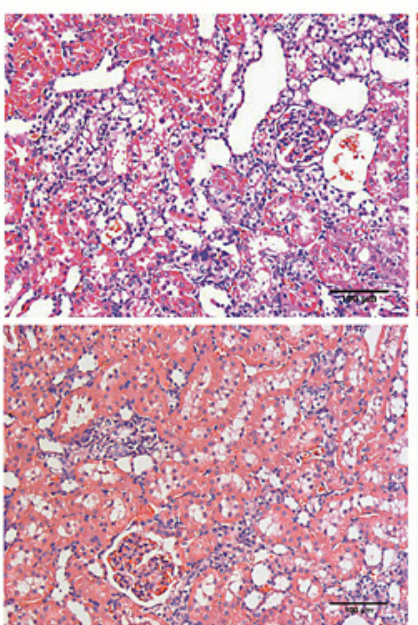

CsA+PFD 250mg/kg/d

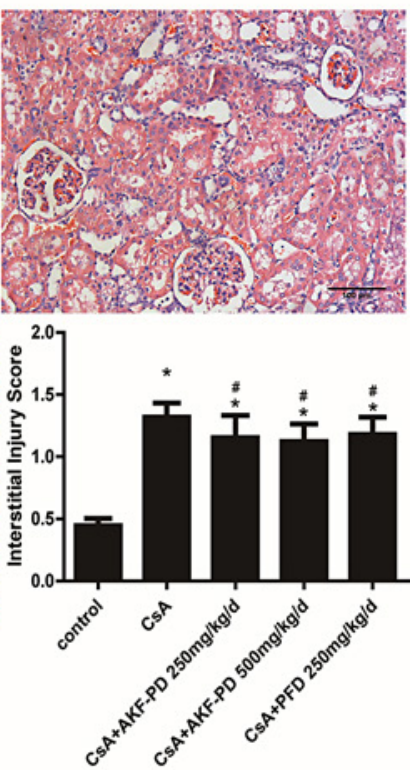

B

control

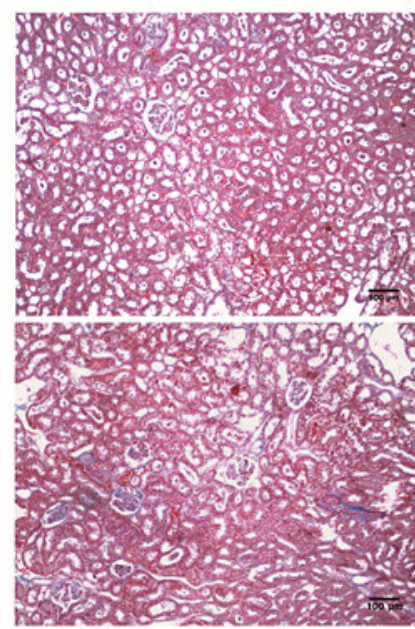

CsA+AKF-PD $500 \mathrm{mg} / \mathrm{kg} / \mathrm{d}$
CsA

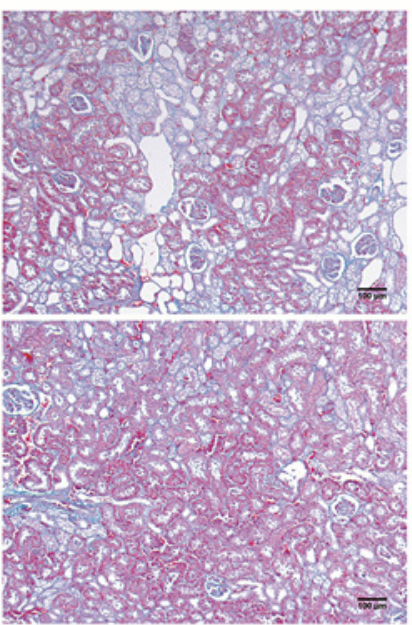

CSA+PFD $250 \mathrm{mg} / \mathrm{kg} / \mathrm{d}$
CsA+AKF-PD 250/mg/kg/d
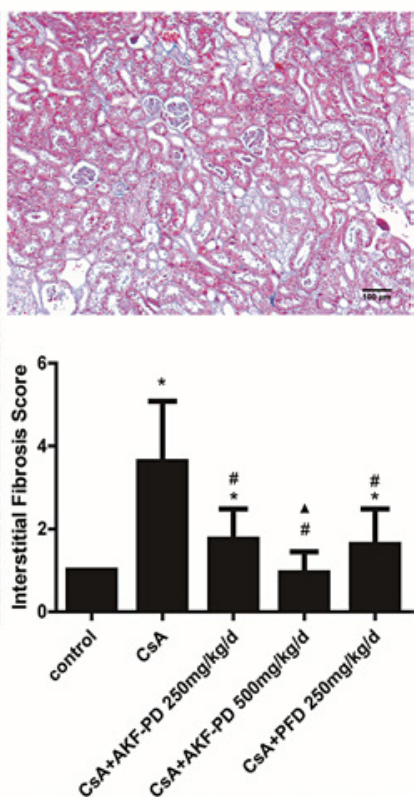

Fig. 1. Representative microscopic findings. A AKF-PD (250, $500 \mathrm{mg} / \mathrm{kg} /$ day) and PFD (250 mg/kg/day) affected tubulointerstitial injury in the CSA-treated kidneys (×200). B AKF-PD (250, $500 \mathrm{mg} / \mathrm{kg} /$ day) and PFD $(250 \mathrm{mg} / \mathrm{kg} / \mathrm{day})$ attenuated the deposition of ECM in the CSA-treated kidneys $(\times 100)$. All data are presented as means $\pm \mathrm{SD}, n=13-17$; $^{*} p<0.05$ versus control, ${ }^{*} p<0.05$ versus CsA, ${ }^{\wedge} p<0.05$ versus PFD 250 $\mathrm{mg} / \mathrm{kg} /$ day. CsA, cyclosporine A; PFD, pirfenidone; AKF-PD, fluorofenidone. 
Kidney

Blood Pressure

Research

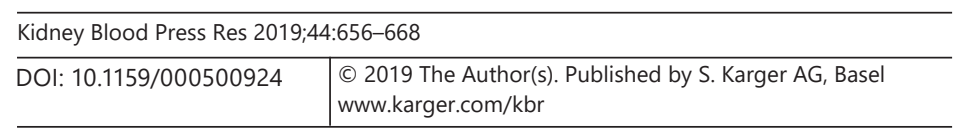

Chen et al.: The Protective Effect of AKF-PD against CsA-Induced Nephrotoxicity

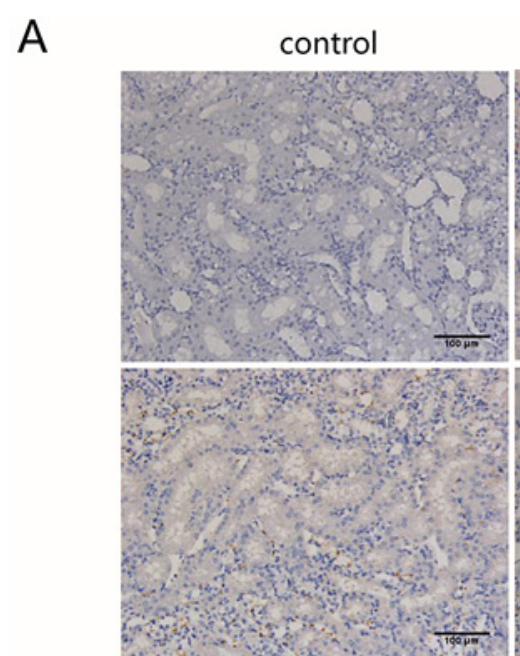

CsA+AKF-PD $500 \mathrm{mg} / \mathrm{kg} / \mathrm{d}$

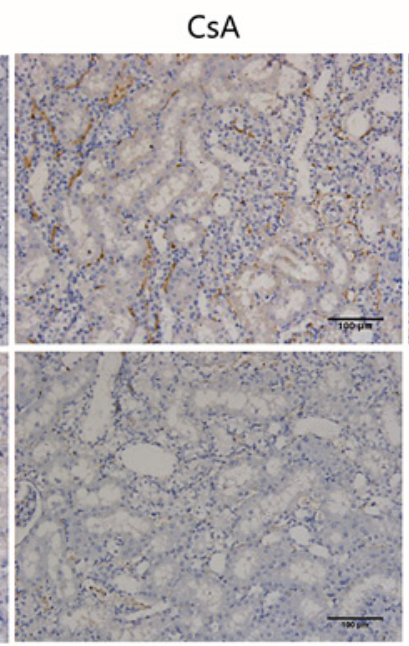

CsA+PFD $250 \mathrm{mg} / \mathrm{kg} / \mathrm{d}$
CsA+AKF-PD 250/mg/kg/d

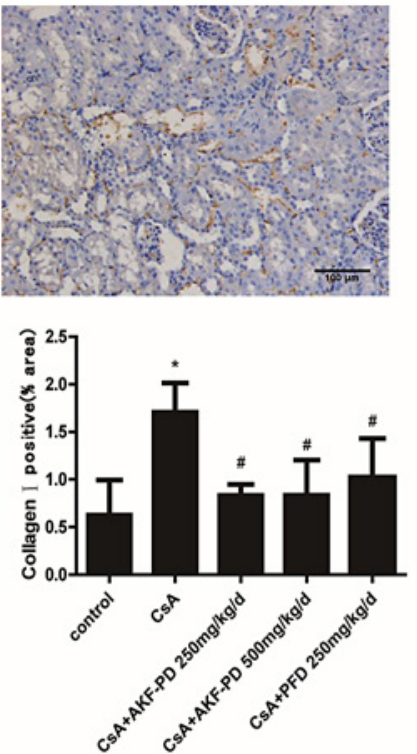

CsA+AKF-PD 250/mg/kg/d
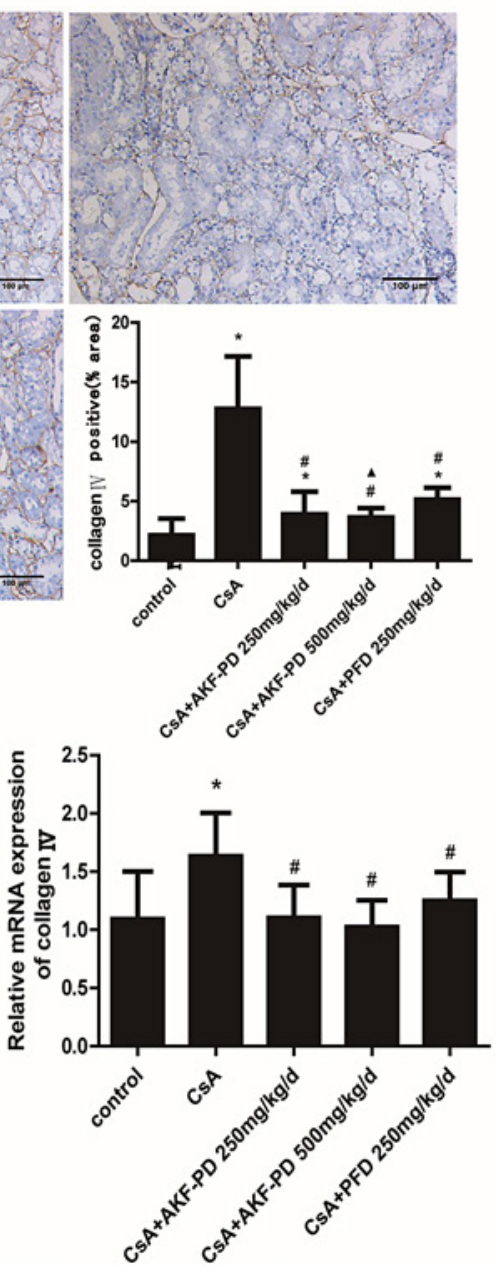

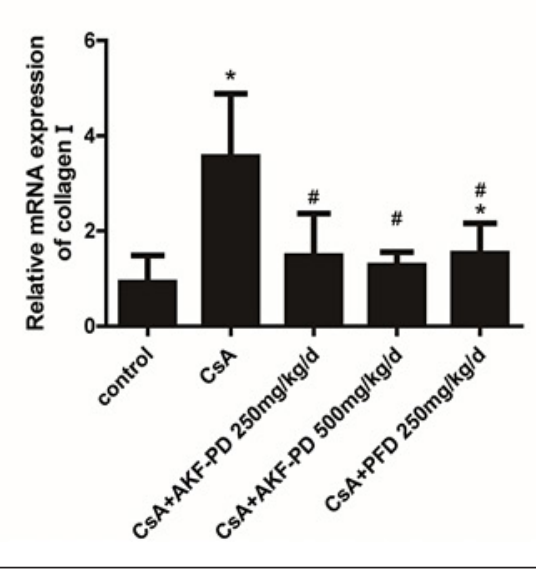

D

C
CsA
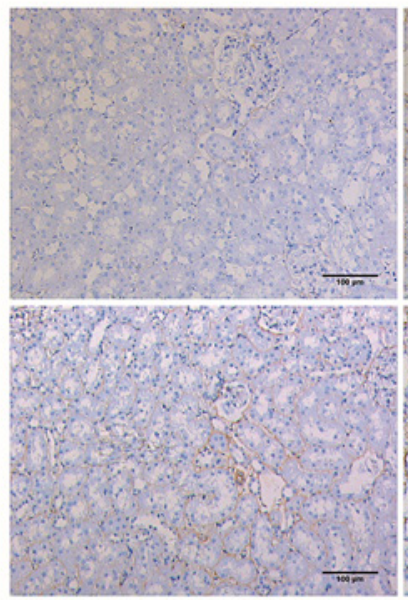

CsA+AKF-PD $500 \mathrm{mg} / \mathrm{kg} / \mathrm{d}$

CsA+PFD $250 \mathrm{mg} / \mathrm{kg} / \mathrm{d}$

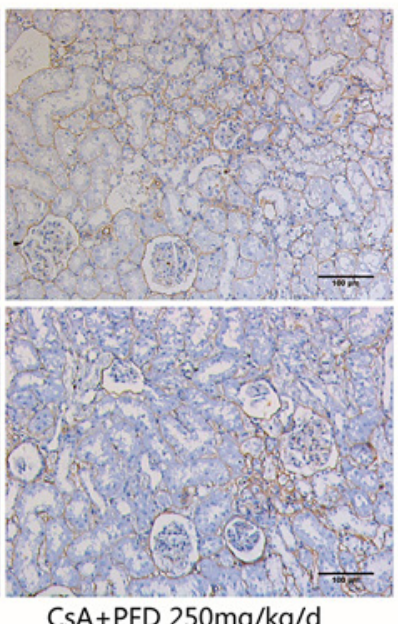

(For legend see next page.) 
revealing that AKF-PD $(250,500 \mathrm{mg} / \mathrm{kg} /$ day $)$ decreased the amount of collagen deposited in the interstitium relative to CsA-treated rats, as did PFD (250 mg/kg/day) treatment (Fig. 1B). Types I and IV collagen are the primary components of the ECM in the kidney that are associated with tubulointerstitial fibrosis. We therefore measured the levels of these collagens via IHC and real-time PCR. AKF-PD (250, $500 \mathrm{mg} / \mathrm{kg} /$ day) and PFD (250 mg/kg/day) resulted in significantly reduced levels of both type I and IV collagen (Fig. 2A-D).

\section{AKF-PD-Inhibited PDGF and TGF- $\beta 1$ Expression in CsA-Induced Nephropathy}

PDGF acts as a mitogenic compound for mesenchymal cells such as myofibroblasts, which are key fibrotic mediators, while TGF- $\beta 1$ further supports this process by stimulating additional collagen deposition from the dividing myofibroblasts [31, 32]. mRNA expression of TGF- $\beta 1$ and PDGF was elevated in CsA-treated rat kidneys, AKF-PD $(250,500 \mathrm{mg} / \mathrm{kg} /$ day), and PFD (250 mg/kg/day) attenuated those effects (Fig 3A, B).

\section{AKF-PD Reduced Apoptosis in CsA-Induced Nephropathy}

To determine the protective effects of AKF-PD on CsA-induced renal tubular apoptosis, we conducted TUNEL staining and found a greater number of TUNEL-positive apoptotic rat kidney cells following CsA treatment relative to vehicle controls. Both AKF-PD (250 and 500 $\mathrm{mg} / \mathrm{kg} /$ day) and PFD (250 mg/kg/day) caused a significant decrease in apoptotic cell numbers in CsA-treated kidneys (Fig. 4A). CsA is also known to induce increases in proapo-

A

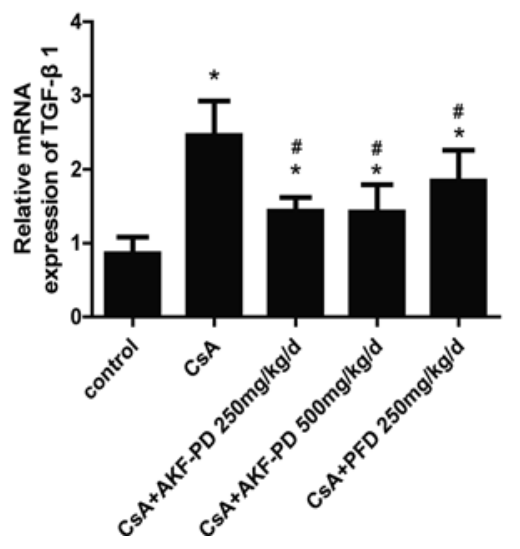

B

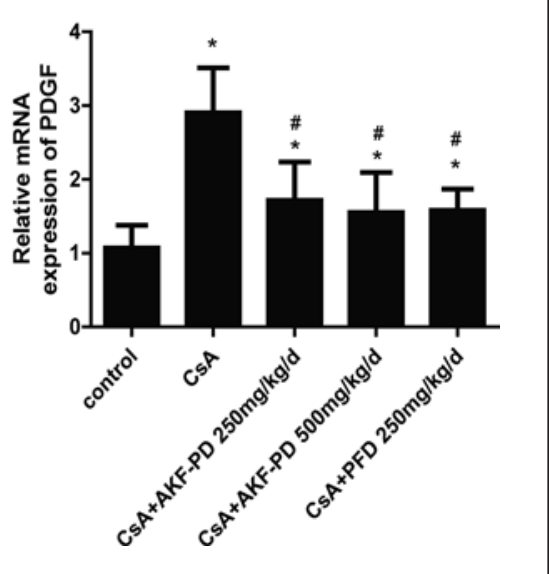

Fig. 3. AKF-PD (250, $500 \mathrm{mg} / \mathrm{kg} /$ day) and PFD (250 mg/kg/day) affected the relative mRNA expression of TGF- $\beta 1$ and PDGF in the CSA-treated kidneys. TGF- $\beta 1$ (A) and PDGF (B) mRNA expression in the kidneys. All data are presented as means $\pm \mathrm{SD}, n=6 .{ }^{*} p<0.05$ versus control, ${ }^{\#} p<0.05$ versus CsA. CsA, cyclosporine A; PFD, pirfenidone; TGF, transforming growth factor; AKF-PD, fluorofenidone.

Fig. 2. AKF-PD (250, $500 \mathrm{mg} / \mathrm{kg} /$ day) and PFD (250 mg/kg/day) affected collagen I and collagen IV protein expression in the CSA-treated kidneys. Collagen I (A) and collagen IV (B) protein expression in the CSA-treated kidneys stained by IHC $(\times 200)$. The histogram was the semiquantitative analysis result of collagen I and IV protein expression in the kidneys. Collagen I (C) and collagen IV (D) mRNA expression in the kidneys. All data are presented as means $\pm \mathrm{SD}, n=6$. $^{*} p<0.05$ versus control, ${ }^{*} p<0.05$ versus $\mathrm{CsA},{ }^{\boldsymbol{\Delta}} p<0.05$ versus $\mathrm{PFD}$ $250 \mathrm{mg} / \mathrm{kg} /$ day. CsA, cyclosporine A; PFD, pirfenidone; AKF-PD, fluorofenidone. 
A
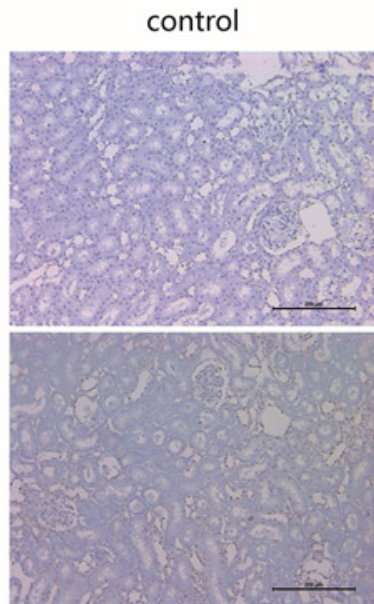

CsA+AKF-PD 500mg/kg/d
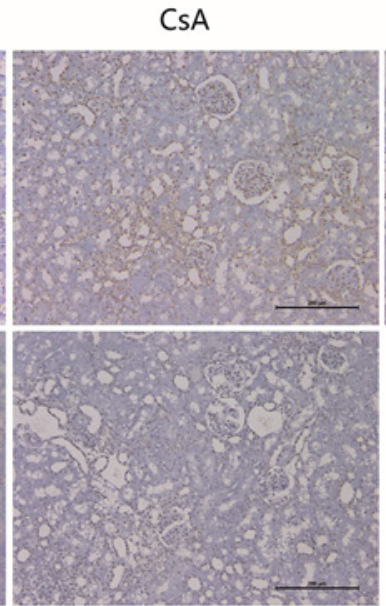

CsA+PFD $250 \mathrm{mg} / \mathrm{kg} / \mathrm{d}$
CSA+AKF-PD 250/mg/kg/d

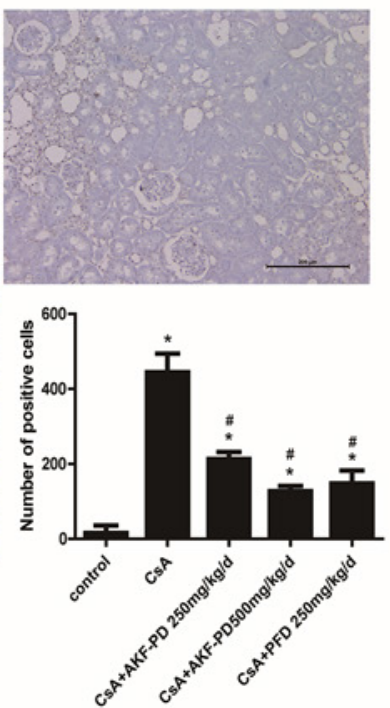

C
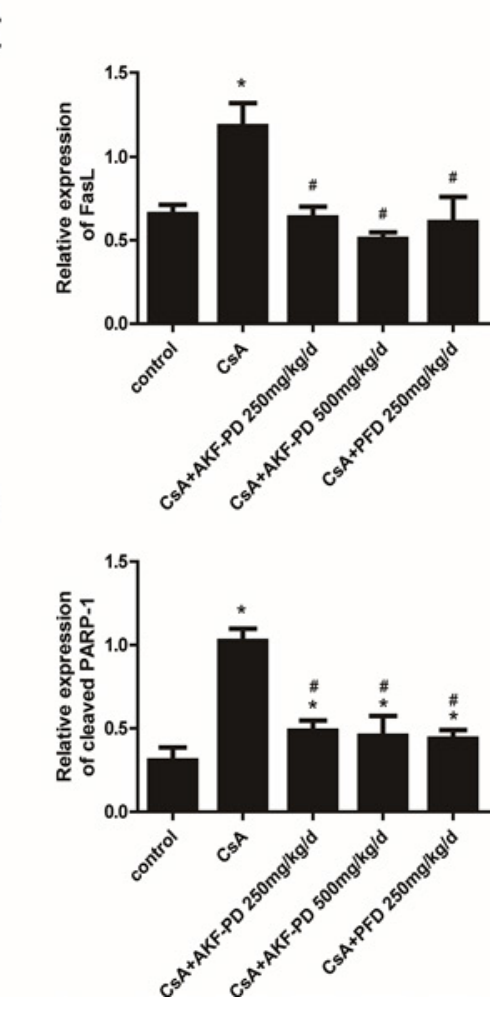

\section{E}

B

FasL
cleaved caspase 3
cleaved PARP-1
GAPDH

CsA

$\mathrm{AKF}-\mathrm{PD}(\mathrm{mg} / \mathrm{kg} / \mathrm{d})$

$\operatorname{PFD}(\mathrm{mg} / \mathrm{kg} / \mathrm{d})$

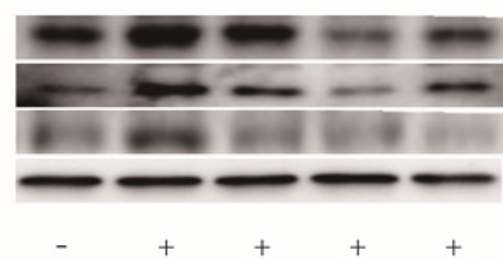

250

D

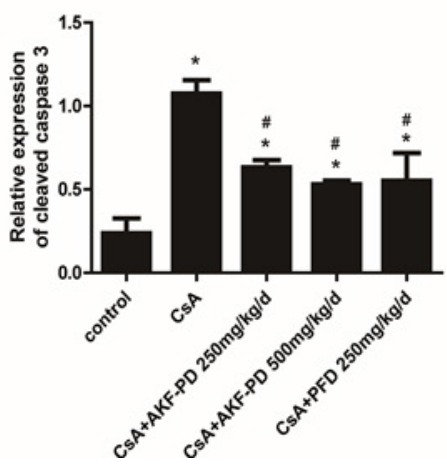

Fig. 4. AKF-PD (250, $500 \mathrm{mg} / \mathrm{kg} /$ day) and PFD (250 mg/kg/day) affected tubular cell apoptosis in the CSAtreated kidneys. A Renal cortex was assayed for apoptosis via TUNEL staining $(\times 100)$. Typical images and quantifications are shown. B Representative Western blot of FasL, cleaved-caspase-3, and cleaved-PARP-1 in rat kidney tissue. Quantitative analysis of FasL (C), cleaved-caspase-3 (D), and cleaved-PARP-1 (E) expression. All data represented as means $\pm \mathrm{SD}, n=3 .{ }^{*} p<0.05$ versus control, ${ }^{\#} p<0.05$ versus CsA. CsA, cyclosporine A; PFD, pirfenidone; FasL, Fas ligand; AKF-PD, fluorofenidone. 


\section{Kidney \\ Blood Pressure \\ Research}

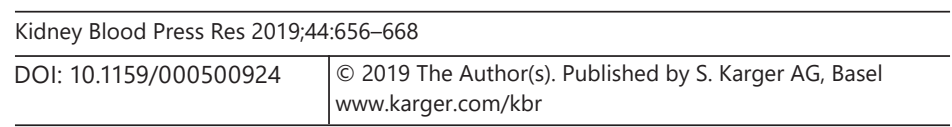

Chen et al.: The Protective Effect of AKF-PD against CsA-Induced Nephrotoxicity

ptotic markers such as FasL and the cleaved forms of caspase-3 and PARP-1, all of which were clearly downregulated in AKF-PD or PFD-treated kidneys (Fig. 4B-E).

AKF-PD Reduced mRNA Expression of TGF- $\beta 1$ and Apoptosis in CsA-Treated NRK-52E Cells

We next sought to determine how AKF-PD influences apoptosis in vitro. First, we found that the mRNA expression of TGF- $\beta 1$ was significantly increased in CsA-treated NRK-52E cells. Whereas, this change was restored by AKF-PD $(400 \mu \mathrm{g} / \mathrm{mL})$ or PFD $(400 \mu \mathrm{g} / \mathrm{mL})$ or TGF- $\beta$ type I receptor inhibitor GW788388 ( $5 \mu \mathrm{mol} / \mathrm{L}$; Fig. 5F). Second, annexin V/PI staining was performed in order to measure the number of apoptotic cells by flow cytometry. As shown in Figure 5A, NRK-52E cells treated with CSA (20 $\mu \mathrm{mol} / \mathrm{L})$ exhibited majority of cells in early apoptotic stage (49.87\%) with $6.15 \%$ in the late apoptosis. Simultaneous treatment with AKF-PD ( $400 \mu \mathrm{g} / \mathrm{mL})$ or PFD $(400 \mu \mathrm{g} / \mathrm{mL})$ or GW788388 $(5 \mu \mathrm{mol} / \mathrm{L})$ and CsA was associated with a marked reduction in such apoptosis (Fig. 5A). Furthermore, western blotting was further performed to assess how treatment with these drugs affected CsA-induced caspase activation, PARP-1 cleavage, and upregulation of FasL. Results showed that FasL expression was increased, and that both caspase-3 and PARP-1 were activated during CsA treatment. AKF-PD ( $400 \mu \mathrm{g} / \mathrm{mL})$, PFD $(400 \mu \mathrm{g} / \mathrm{mL})$, or GW788388 $(5 \mu \mathrm{mol} / \mathrm{L})$ administration significantly reduced all 3 of these apoptotic indicators (Fig. 5B-E).

\section{Discussion}

Herein we demonstrated that AKF-PD remarkably attenuates kidney injury induced by CsA. AKF-PD administration prevented tubulointerstitial fibrosis and further led to a reduction in renal tubular epithelial cell apoptosis. Signaling and protein production associated with fibrotic activity and apoptosis were similarly reduced by these agents.

Chronic CsA nephrotoxicity is linked to striped interstitial fibrosis, tubular atrophy, and afferent arteriole hyalinosis [33]. In order to assess the antifibrotic activities of AKF-PD, we investigated ECM deposition and tubulointerstitial injury scores in rats that had been treated with CsA. We found that AKF-PD treatment reduced both of these pathogenic indices, and assessments of type I and IV collagen levels further confirmed the ability of this drug to protect against fibrogenesis in the context of chronic CsA administration.

During normal kidney development, apoptosis is important for maintaining normal tissue function [33,34]. However, when apoptosis remains unchecked, it can lead to extensive and gradual kidney cell loss, culminating in renal tubular atrophy and fibrotic tubulointerstitial scarring [35]. The apoptotic death of tubular cells can ultimately create an ideal local microenvironment for the proliferation and activation of myofibroblasts and other fibrogenic cells owing to local transdifferentiation [36]. Significantly elevated apoptotic tubular cells were observed in renal biopsy specimens obtained from patients with CsA nephrotoxicity [37]. In this study, we found that the number of cells undergoing apoptosis increased in the tubular

Fig. 5. AKF-PD ( $400 \mu \mathrm{g} / \mathrm{mL})$, PFD $(400 \mu \mathrm{g} / \mathrm{mL})$, and GW788388 (5 $\mu \mathrm{mol} / \mathrm{L})$ suppressed apoptosis and mRNA expression of TGF- $\beta 1$ induced by CsA in NRK-52E cells. A Percentages of apoptotic cells determined by FACS analysis using annexin V-FITC and PI. B Representative Western blot of FasL, cleaved-caspase-3 and cleavedPARP-1 in NRK-52E cells. Quantitative analysis of FasL (C), cleaved-caspase-3 (D), and cleaved-PARP-1 (E) expression in NRK-52E cells $(n=3)$. $\mathbf{F}$ The relative mRNA expression of TGF- $\beta 1$ in NRK-52E cells $(n=6)$. All data are presented as means \pm SD. ${ }^{*} p<0.05$ versus control, ${ }^{\#} p<0.05$ versus CsA. ${ }^{\wedge} p<0.05$ versus AKF-PD $400 \mu \mathrm{g} / \mathrm{mL}$. CsA, cyclosporine A; PFD, pirfenidone; TGF, transforming growth factor; FasL, Fas ligand; AKF$\mathrm{PD}$, fluorofenidone.

(For figure see next page.) 
Kidney

Blood Pressure

Research
Kidney Blood Press Res 2019;44:656-668

A
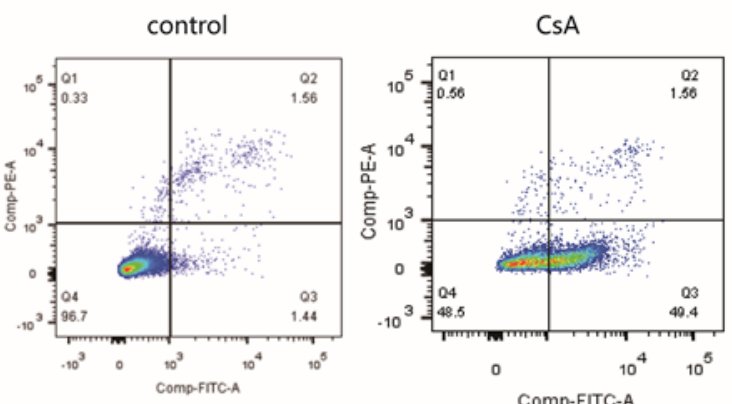

(C) 2019 The Author
www.karger.com/kb

Chen et al.: The Protective Effect of AKF-PD against CsA-Induced Nephrotoxicity

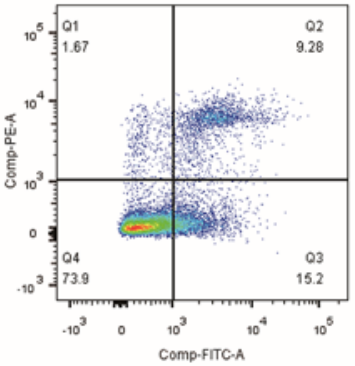

CSA+PFD $400 \mu \mathrm{g} / \mathrm{ml}$

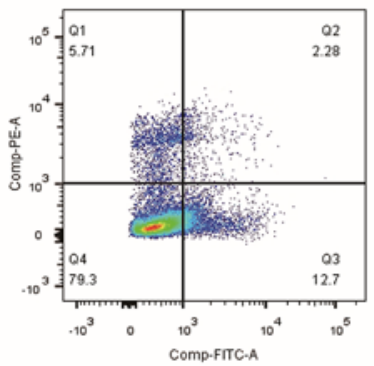

GW788388 5 $\mu \mathrm{mol} / \mathrm{l}$
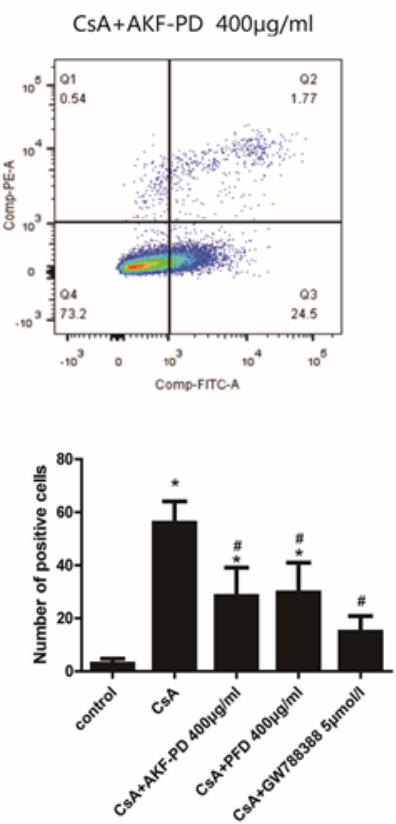

C

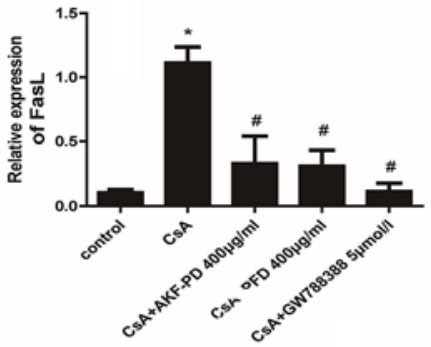

E

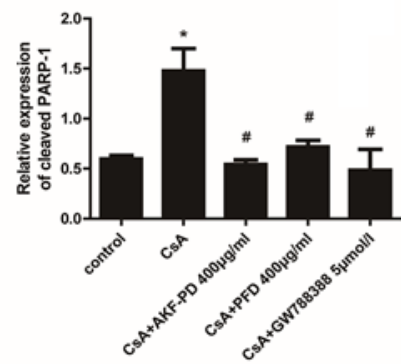

$\mathrm{F}$
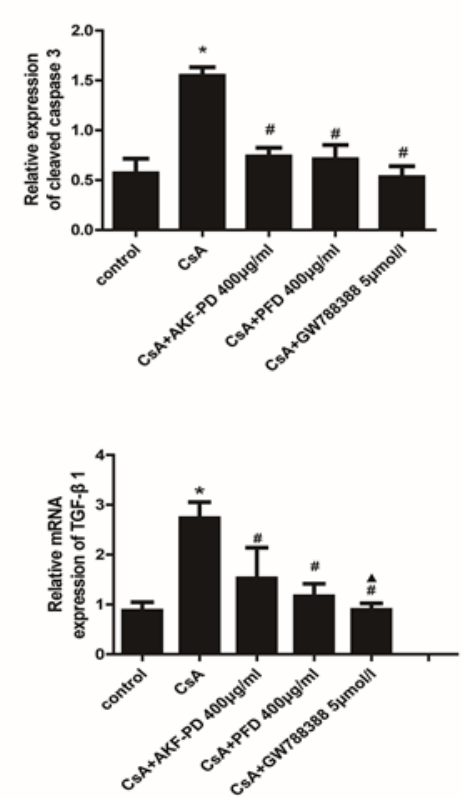

$\begin{array}{cccccc}\mathrm{AKF}-\mathrm{PD}(\mu \mathrm{g} / \mathrm{ml}) & - & - & 400 & - & - \\ \mathrm{PFD}(\mu \mathrm{g} / \mathrm{ml}) & - & - & - & 400 & - \\ \mathrm{GW788388}(\mu \mathrm{mol} / \mathrm{l}) & - & - & - & - & 5\end{array}$

D

FasL

leaved caspase 3

GAPDH

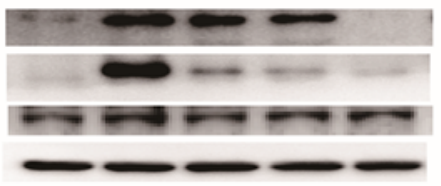

CsA 


\section{Kidney \\ Blood Pressure \\ Research}

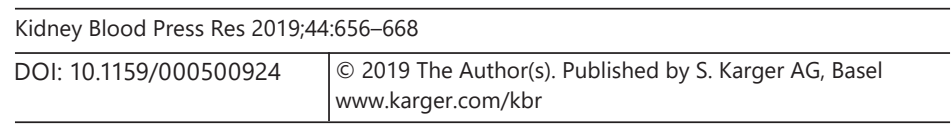

Chen et al.: The Protective Effect of AKF-PD against CsA-Induced Nephrotoxicity

region upon CsA treatment. Consistent with the results of TUNEL staining of kidney samples, annexin V-PI staining of NRK-52E cells revealed an increase in apoptotic cells following CsA treatment. In both instances, AKF-PD significantly reduced the number of apoptotic cells. The cell surface receptor Fas and its ligand are key apoptotic mediators [38]. Caspase-3 activation similarly acts as a vital step in the process of determining whether or not a cell will progress to apoptosis, signaling via PARP-1. PARP- 1 itself is degraded by caspase- 3 into 2 cleavage fragments [39]. Our study suggests that the FasL, caspase-3, and PARP-1 are all implicated in CsAinduced apoptosis. AKF-PD significantly reduced the expression and/or activity of these apoptotic genes in both CsA-treated rats and NRK-52E cells.

TGF- $\beta 1$ is also believed to be a key player in the development of renal fibrosis, both promoting EMT and apoptosis in renal tubule cells and activating local myofibroblasts and epithelial cells that then produce additional ECM components and impair ECM degradation [40]. There is evidence to suggest that TGF- $\beta 1$ can enhance Fas-mediated apoptosis in primary cultured bronchiolar epithelial cells [41]. Similarly, TGF- $\beta 1$ also enhances Fas and FasL expression in NRK-52E cells [15]. In this study, we showed that AKF-PD could suppress the mRNA expression of TGF- $\beta 1$ induced by CsA treatment in NRK-52E cells and rats. Moreover, administration of TGF- $\beta$ type I receptor inhibitor GW788388 significantly reduced the number of apoptotic cells and FasL/caspase-3 expression. As such, our observations revealed that TGF- $\beta 1$ is an important mediator of CSA-induced FasL/caspase- 3 activation, and AKF-PD could suppress apoptosis induced by CsA partly through inhibition of TGF- $\beta 1$ signals.

PDGF is involved in mediating renal fibrosis, as it is normally expressed at low levels in healthy adult kidneys, but this expression is elevated in the context of fibrogenesis [42, 43]. In this study, we found that the level of PDGF was increased in kidneys during CsA treatment. Previous study indicated that CsA induced accumulation of PDGF mainly in the walls of renal arterioles [44]. Therefore, we prospected AKF-PD inhibited PDGF expression in CsA-treated kidney possibly by affecting vasoconstriction of renal arterioles.

PFD is an antifibrotic molecule that was shown to prevent fibrosis effectively. It has been reported to attenuate renal fibrosis [26], preventing tubular cell apoptosis in a rat model CsAinduced chronic nephrotoxicity. AKF-PD has the similar chemical structure with PFD, but the difference of its molecular structure from that of PFD is that one hydrogen atom at the metaposition of the benzene ring in PFD is replaced by a fluorine atom in AKF-PD. Since fluorine features the highest electronegativity among all elements and the carbon - fluorine bond has considerable stability, while the toxicity of AKF-PD was poorer [27]. Our finding indicated that these 2 drugs have similar therapeutic effects against CsA-induced nephrotoxicity by decreasing the expression of proapoptotic proteins and ECM deposition.

In summary, our findings show that AKF-PD attenuates experimental CsA-induced kidney injuries through antifibrotic and antiapoptotic effects. AKF-PD therefore may represent an alternative or additional therapeutic approach for CsA-induced nephrotoxicity.

\section{Acknowledgement}

This project was supported by the National Natural Science Foundation of China (grant nos. 81302210, 81873585, and 81400749) and Natural Science Foundation of Hunan Province, China (grant no. 2018JJ3835).

\section{Statement of Ethics}

All animal protocols were compliant with NIH guidelines and met with the approval of the Institutional Animal Care and Use Committee of Xiangya Hospital, Central South University. 


\section{Kidney \\ Blood Pressure \\ Research}

\begin{tabular}{l|l}
\hline Kidney Blood Press Res 2019;44:656-668 \\
\hline DOI: 10.1159/000500924 & $\begin{array}{l}\text { @ 2019 The Author(s). Published by S. Karger AG, Basel } \\
\text { www.karger.com/kbr }\end{array}$ \\
\hline
\end{tabular}

Chen et al.: The Protective Effect of AKF-PD against CSA-Induced Nephrotoxicity

\section{Disclosure Statement}

The authors have no conflicts of interest to disclose.

\section{References}

1 Bennett WM, Norman DJ. Action and toxicity of cyclosporine. Annu Rev Med. 1986;37(1):215-24.

2 Mohapatra N, Vanikar AV, Patel RD, Trivedi HL. Modifying cyclosporine associated renal allograft dysfunction. Saudi J Kidney Dis Transpl. 2009 Sep;20(5):770-4.

3 Myers BD, Ross J, Newton L, Luetscher J, Perlroth M. Cyclosporine-associated chronic nephropathy. N Engl J Med. 1984 Sep;311(11):699-705.

4 Naesens M, Kuypers DR, Sarwal M. Calcineurin inhibitor nephrotoxicity. Clin J Am Soc Nephrol. 2009 Feb; 4(2): 481-508.

5 Brunner T, Mogil RJ, LaFace D, Yoo NJ, Mahboubi A, Echeverri F, et al. Cell-autonomous Fas (CD95)/Fas-ligand interaction mediates activation-induced apoptosis in T-cell hybridomas. Nature. 1995 Feb;373(6513):441-4.

6 Zhao J, Duan S, Zhou J, Sun R, Zhang L, Wang D. Mild hypothermia reduces expression of Fas/FasL and MMP-3 after cerebral ischemia-reperfusion in rats. Iran J Basic Med Sci. 2014 Jun;17(6):454-9.

7 Krammer PH, Arnold R, Lavrik IN. Life and death in peripheral T cells. Nat Rev Immunol. 2007 Jul;7 (7):532-42.

8 Nagata S. Fas-induced apoptosis. Intern Med. 1998 Feb;37(2):179-81.

9 Johnson DW, Saunders HJ, Johnson FJ, Huq SO, Field MJ, Pollock CA. Cyclosporin exerts a direct fibrogenic effect on human tubulointerstitial cells: roles of insulin-like growth factor I, transforming growth factor beta1, and platelet-derived growth factor. J Pharmacol Exp Ther. 1999 Apr;289(1):535-42.

10 Vieira JM Jr, Noronha IL, Malheiros DM, Burdmann EA. Cyclosporine-induced interstitial fibrosis and arteriolar TGF-beta expression with preserved renal blood flow. Transplantation. 1999 Dec;68(11):1746-53.

11 Border WA, Noble NA. TGF-beta in kidney fibrosis: a target for gene therapy. Kidney Int. 1997 May;51(5): 1388-96.

12 Choi YJ, Baranowska-Daca E, Nguyen V, Koji T, Ballantyne CM, Sheikh-Hamad D, et al. Mechanism of chronic obstructive uropathy: increased expression of apoptosis-promoting molecules. Kidney Int. 2000 Oct;58(4): 1481-91.

13 Truong LD, Choi YJ, Tsao CC, Ayala G, Sheikh-Hamad D, Nassar G, et al. Renal cell apoptosis in chronic obstructive uropathy: the roles of caspases. Kidney Int. 2001 Sep;60(3):924-34.

14 Yang B, Johnson TS, Thomas GL, Watson PF, Wagner B, Skill NJ, et al. Expression of apoptosis-related genes and proteins in experimental chronic renal scarring. J Am Soc Nephrol. 2001 Feb;12(2):275-88.

15 Yu Z, Zai-Chun X, Wun-Lun H, Yun-Yun Z. BMP-7 Attenuates TGF- $\beta 1$-Induced Fibronectin Secretion and Apoptosis of NRK-52E Cells by the Suppression of miRNA-21. Oncol Res. 2016;23(4):147-54.

16 Li BX, Tang YT, Wang W, Xie YY, Wang NS, Yuan QJ, et al. Fluorofenidone attenuates renal interstitial fibrosis in the rat model of obstructive nephropathy. Mol Cell Biochem. 2011 Aug;354(1-2):263-73.

17 Yuan Q, Wang R, Peng Y, Fu X, Wang W, Wang L, et al. Fluorofenidone attenuates tubulointerstitial fibrosis by inhibiting TGF- $\beta(1)$-induced fibroblast activation. Am J Nephrol. 2011;34(2):181-94.

18 Qin J, Xie YY, Huang L, Yuan QJ, Mei WJ, Yuan XN, et al. Fluorofenidone inhibits nicotinamide adeninedinucleotide phosphate oxidase via PI3K/Akt pathway in the pathogenesis of renal interstitial fibrosis. Nephrology (Carlton). 2013 Oct;18(10):690-9.

19 Yuan Q, Wang L, Zhang F, Wang R, Fu X, Peng Z, et al. Fluorofenidone suppresses epithelial-mesenchymal transition and the expression of connective tissue growth factor via inhibiting TGF-beta/Smads signaling in human proximal tubular epithelial cells. Pharmazie. 2011 Dec;66(12):961-7.

20 Peng ZZ, Hu GY, Shen H, Wang L, Ning WB, Xie YY, et al. Fluorofenidone attenuates collagen I and transforming growth factor-beta1 expression through a nicotinamide adenine dinucleotide phosphate oxidase-dependent way in NRK-52E cells. Nephrology (Carlton). 2009 Sep;14(6):565-72.

21 Liu J, Song C, Xiao Q, Hu G, Tao L, Meng J. Fluorofenidone attenuates TGF- $\beta 1$-induced lung fibroblast activation via restoring the expression of caveolin-1. Shock. 2015 Feb;43(2):201-7.

22 Meng J, Zou Y, Hu C, Zhu Y, Peng Z, Hu G, et al. Fluorofenidone attenuates bleomycin-induced pulmonary inflammation and fibrosis in mice via restoring caveolin 1 expression and inhibiting mitogen-activated protein kinase signaling pathway. Shock. 2012 Nov;38(5):567-73.

23 Peng Y, Yang H, Wang N, Ouyang Y, Yi Y, Liao L, et al. Fluorofenidone attenuates hepatic fibrosis by suppressing the proliferation and activation of hepatic stellate cells. Am J Physiol Gastrointest Liver Physiol. 2014 Feb; 306(3):G253-63.

24 Peng Y, Yang H, Zhu T, Zhao M, Deng Y, Liu B, et al. The antihepatic fibrotic effects of fluorofenidone via MAPK signalling pathways. Eur J Clin Invest. 2013 Apr;43(4):358-68.

25 Ning WB, Hu GY, Peng ZZ, Wang L, Wang W, Chen JY, et al. Fluorofenidone inhibits Ang II-induced apoptosis of renal tubular cells through blockage of the Fas/FasL pathway. Int Immunopharmacol. 2011 Sep;11(9): 1327-32. 
26 Shihab FS, Bennett WM, Yi H, Andoh TF. Effect of pirfenidone on apoptosis-regulatory genes in chronic cyclosporine nephrotoxicity. Transplantation. 2005 Feb;79(4):419-26.

27 Cao W, He L, Liu W, Huang Z, Cheng Z. Determination of AKF-PD in whole blood of rat by HPLC-UV. J Chromatogr B Analyt Technol Biomed Life Sci. 2006 Apr;833(2):257-9.

28 Radford MG Jr, Donadio JV Jr, Bergstralh EJ, Grande JP. Predicting renal outcome in IgA nephropathy. J Am Soc Nephrol. 1997 Feb;8(2):199-207.

29 Lin SL, Chen RH, Chen YM, Chiang WC, Lai CF, Wu KD, et al. Pentoxifylline attenuates tubulointerstitial fibrosis by blocking Smad3/4-activated transcription and profibrogenic effects of connective tissue growth factor. J Am Soc Nephrol. 2005 Sep;16(9):2702-13.

30 Wang LH, Liu JS, Ning WB, Yuan QJ, Zhang FF, Peng ZZ, et al. Fluorofenidone attenuates diabetic nephropathy and kidney fibrosis in db/db mice. Pharmacology. 2011;88(1-2):88-99.

31 Bonner JC. Regulation of PDGF and its receptors in fibrotic diseases. Cytokine Growth Factor Rev. 2004 Aug; 15(4):255-73.

32 Bonner JC, Brody AR. Cytokine-binding proteins in the lung. Am J Physiol. 1995 Jun;268(6 Pt 1):L869-78.

33 Shihab FS, Andoh TF, Tanner AM, Yi H, Bennett WM. Expression of apoptosis regulatory genes in chronic cyclosporine nephrotoxicity favors apoptosis. Kidney Int. 1999 Dec;56(6):2147-59.

34 Servais H, Ortiz A, Devuyst O, Denamur S, Tulkens PM, Mingeot-Leclercq MP. Renal cell apoptosis induced by nephrotoxic drugs: cellular and molecular mechanisms and potential approaches to modulation. Apoptosis. 2008 Jan;13(1):11-32.

35 Hauser P, Oberbauer R. Tubular apoptosis in the pathophysiology of renal disease. Wien Klin Wochenschr. 2002 Aug;114(15-16):671-7.

36 Razzaque MS, Ahsan N, Taguchi T. Role of apoptosis in fibrogenesis. Nephron. 2002 Apr;90(4):365-72.

37 Ito H, Kasagi N, Shomori K, Osaki M, Adachi H. Apoptosis in the human allografted kidney. Analysis by terminal deoxynucleotidyl transferase-mediated DUTP-botin nick end labeling. Transplantation. 1995 Oct;60(8): 794-8.

38 Nagata S, Golstein P. The Fas death factor. Science. 1995 Mar;267(5203):1449-56.

39 Lupachyk S, Shevalye H, Maksimchyk Y, Drel VR, Obrosova IG. PARP inhibition alleviates diabetes-induced systemic oxidative stress and neural tissue 4-hydroxynonenal adduct accumulation: correlation with peripheral nerve function. Free Radic Biol Med. 2011 May;50(10):1400-9.

40 García-Sánchez 0, López-Hernández FJ, López-Novoa JM. An integrative view on the role of TGF-beta in the progressive tubular deletion associated with chronic kidney disease. Kidney Int. 2010 Jun;77(11):950-5.

41 Hagimoto N, Kuwano K, Inoshima I, Yoshimi M, Nakamura N, Fujita M, et al. TGF-beta 1 as an enhancer of Fasmediated apoptosis of lung epithelial cells. J Immunol. 2002 Jun;168(12):6470-8.

42 Alpers CE, Seifert RA, Hudkins KL, Johnson RJ, Bowen-Pope DF. Developmental patterns of PDGF B-chain, PDGF-receptor, and alpha-actin expression in human glomerulogenesis. Kidney Int. 1992 Aug;42(2):390-9.

43 Abboud HE. Role of platelet-derived growth factor in renal injury. Annu Rev Physiol. 1995;57(1):297-309.

44 Shehata M, el Nahas A, Barkworth E, Cope GH, Raftery AT. Increased platelet-derived growth factor in the kidneys of cyclosporin-treated rats. Kidney Int. 1994 Sep;46(3):726-32. 